Revista Brasileira de

Engenharia Agrícola e Ambiental

v.16, n.5, p.514-520, 2012

Campina Grande, PB, UAEA/UFCG - http://www.agriambi.com.br

agriambi Protocolo 137.11 - 24/06/2011 • Aprovado em 23/02/2012

\title{
Desempenho de cultivares de cenoura em função da água no solo ${ }^{1}$
}

\author{
Joaquim A. Lima Junior ${ }^{2}$, Geraldo M. Pereira ${ }^{3}$, Luciano 0 . G eisenhoff ${ }^{4}$, \\ Wellington G. da Silva ${ }^{3}$, Renato C. Vilas Boas $^{3} \&$ Rovilson J. de Souza ${ }^{5}$
}

RESU M O

O bjetivou-se, com este estudo, avaliar o efeito de diferentes tensões da água no solo sobre a produção de duas cultivares de cenoura irrigadas por gotejamento. O experimento foi conduzido em Lavras,

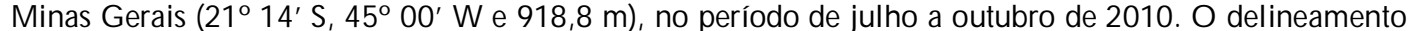
experimental utilizado foi em blocos casual izados, em esquema fatorial $2 \times 6$, com quatro repetições. $\mathrm{Os}$ tratamentos se constituíram de duas cultivares de cenoura, cultivar não híbrida Nantes e cultivar hibrida $\mathrm{N}$ ayarit $\mathrm{F1}$, além de seis níveis críticos de tensão da água no solo, 15, 25, 35, 45, 60 e $75 \mathrm{kPa}$. Com os resultados concluiu-se que o híbrido Nayarit F1 apresentou melhores respostas com relação às seguintes características analisadas: produtividade total de raízes, produtividade de raízes comerciais, massa média de raízes comerciais e eficiência no uso da água. Visando à obtenção de maiores produtividades de raízes (total e comercial) e maior massa média de raízes comerciais, em ambas as cultivares, deve-se irrigar no momento em que a tensão da água no solo estiver em torno de $15 \mathrm{kPa}$ na profundidade de $0,15 \mathrm{~m}$. 0 valor mínimo encontrado para a raízes do tipo refugo ocorreu na tensão de $21 \mathrm{kPa}$, resultando em um valor mínimo de massa raiz de $41,67 \mathrm{~g}$.

Palavras-chave: Daucus carota L., irrigação localizada, tensiômetro

\section{Performance of carrot cultivars depending on soil water}

\begin{abstract}
A B STRACT
Different soil water tension values were tested to evaluate the effects on yield of two drip irrigated carrot cultivars. The experiment was carried out at Lavras, in the State of M inas G erais, Brazil (21ㅇ 14' S, 450 00' $\mathrm{W}$ and $918.8 \mathrm{~m}$ ), from July to 0 ctober 2008 . The statistical design used was randomized blocks in a $2 \mathrm{x}$ 6 factorial scheme with four replications. The treatments consisted of two cultivars of carrot (hibrid in Nayarit F1 and non hybrid Nantes) and six critical soil water tension levels (15, 25, 35, 45, 60 and 75 $\mathrm{kPa}$ ). It can be concluded that the hybrid $\mathrm{N}$ ayarit F1 presented the best response in relation to the following analyzed variables: total root yield, marketable root yield, average marketable root mass and water use efficiency. In order to obtain larger root yield (total and marketable) and average marketable root mass, for both cultivars, the irrigation should be provided when soil water tension reaches $15 \mathrm{kPa}$ at $0.15 \mathrm{~m}$ depth. The minimum value found for the roots of non comercial value occurred at a tension of 21 $\mathrm{kPa}$, resulting in a low root mass of $41.67 \mathrm{~g}$.
\end{abstract}

Key words: Daucus carota L., trickle irrigation, tensiometer

\footnotetext{
${ }_{1}^{1}$ Parte da Tese de Doutorado do primeiro autor

2 D CEE/U FRA/Campus Paragominas, Rod. PA 256, km 06, Bairro Nova Conquista, s/n, CP 917, CEP 68625-000, Paragominas, PA. Fone: (91) 3729-4851. E-mail: joaquim.junior@ufra.edu.br

${ }^{3}$ DEG/U FLA, Campus Universitário, CEP 37200-000, Lavras, M G. Fone: (35) 3829-1389. E-mail: geraldop@ufla.br; notgnillew 1111@hotmail.com; renatovilasboas@yahoo.com.br

${ }^{4}$ FCA/U FG D, Rua João Rosa Goes, 1761, Vila Progresso, CEP 79825-070, D ourados, MS. Fone: (67) 3410-2352. E-mail: lucianogeisenhoff@ig.com.br ${ }^{5}$ DAG/U FLA, Campus Universitário, CEP 37200-000, Lavras, MG. Fone: (35) 3829-1779. E-mail: rovilson@ dag.ufla.br
} 


\section{INTRODUÇÃO}

No Brasil, o cultivo da cenoura está entre as dez hortaliças mais importantes em termos mundiais, seja considerando-se a área de plantio ou o valor da produção (Simon, 2000). Em 2005 a produção mundial aproximou-se de 24 milhões de toneladas ocupando uma área de aproximadamente 1,1 milhão de hectare. Segundos dados do Centro de Estudos Avançados em Economia Aplicada, a produtividade média da safra 2008/09, dos estados de Minas Gerais e Distrito Federal, foi de 50 t ha $^{-1}$. Esta cultura, além de absorver grande quantidade de mão-deobra, principalmente a não especializada, contribui com bom retorno financeiro, desde que haja um planejamento adequado desse cultivo.

A irrigação da cenoura (Daucus carota L.), além de ser um importante fator de produção, como na maioria das olerícolas, é o que mais favorece o aumento da produtividade e o aprimoramento da qualidade do produto. Entretanto, o déficit e/ou excesso de água, tal como o modo de aplicação (aspersão, gotejamento), podem propiciar condições desfavoráveis ao desenvolvimento da cenoura e levar à queda na produtividade dessa cultura, além de aumentar os custos com energia de bombeamento e fertilizantes, ao se trabalhar com baixa eficiência de irrigação e de fertirrigação, podendo até mesmo resultar na contaminação dos recursos hídricos (por agrotóxicos e fertilizantes), pelo escoamento superficial resultante da irrigação por aspersão.

Utilizando-se a tensão da água no solo para o manejo da irrigação, vê-se que a irrigação deve ser realizada toda vez em que a tensão atingir determinado valor crítico que não afete o desempenho da cultura Vilas-Boas et al. (2011). Segundo Morgan et al. (2001), o teor de água do solo deve ser mantido entre certos limites específicos acima e abaixo, cuja água disponível para a planta não seja limitada enquanto a lixiviação é prevenida. Conhecendo-se quando irrigar pela tensão da água no solo por meio do tensiômetro, é estabelecido o quanto de água deve ser aplicado pela irrigação, com base no armazenamento de água no solo.

Para maximizar a produtividade de raízes comercializáveis de cenoura, Marouelli et al. (2007) recomendam que as irrigações devem ser realizadas quando a tensão-limite (avaliada na região correspondente a $50 \%$ da profundidade efetiva das raízes) atingir de 10 a $15 \mathrm{kPa}$, para solos de textura arenosa e de 20 a 40 $\mathrm{kPa}$, para solos de textura média e fina. Os maiores valores dentro de cada classe textural, devem ser tomados como limite para reposição de água nos estádios mais tolerantes ao défice hídrico. Para irrigação via gotejamento o solo deve ser mantido com maior teor de água, devendo-se considerar a faixa de tensão-limite entre 7 e $20 \mathrm{kPa}$ como ideal.

Do pegamento das raízes até a paralisação das irrigações, Shock et al. (2002) recomendam irrigar quando a tensão matricial atingir entre 15 e $30 \mathrm{kPa}$. Para evitar problemas de excesso de água junto ao colo das plantas e de doenças de solo, os gotejadores devem ser posicionados de 10 a $25 \mathrm{~cm}$ das raízes, sendo o menor valor para solos com faixa molhada estreita.

No Brasil e particularmente nas regiões de cultivo dessa hortaliça em Minas Gerais, estudos sobre a produção da cenoura irrigada por gotejamento ainda são escassos, sobretudo no aspecto do manejo adequado da irrigação, ou seja, o momento oportuno de irrigar e a quantidade de água a ser aplicada. Esses estudos devem ser realizados próximo às áreas de cultivo, com o objetivo de aquisição de informações mais precisas da necessidade hídrica da cultura.

Em nível nacional os sistemas por aspersão ainda são os mais utilizados no cultivo da cenoura sendo que, nos últimos ano e, em grandes áreas, o sistema pivô central vem sendo utilizado com sucesso nas lavoras de cenoura; no entanto, em virtude da preocupação, em nível mundial, com a questão do gerenciamento, conservação e economia dos recursos hídricos, tem-se recomendado, para a grande maioria das culturas, o uso do método de irrigação localizada (sistemas de microaspersão e gotejamento), por ser mais eficiente na aplicação de água e de fertilizantes (Nogueira et al., 1998).

Com base no exposto objetivou-se, com este estudo, avaliar o efeito de diferentes tensões da água no solo sobre a produção de duas cultivares de cenoura irrigadas por gotejamento.

\section{MATERIAL E MÉTODOS}

O experimento foi conduzido entre os meses de julho e outubro de 2010, em canteiros construídos a céu aberto, na área experimental do Departamento de Engenharia da Universidade Federal de Lavras (UFLA), localizada no município de Lavras, sul de Minas Gerais, tendo como referência as seguintes coordenadas geográficas: latitude $21^{\circ} 14^{\prime} \mathrm{S}$, longitude $45^{\circ} 00^{\prime}$ ' W e $918,8 \mathrm{~m}$ de altitude.

De acordo com a classificação climática de Köppen (Dantas et al., 2007), o clima de Lavras é Cwa, ou seja, clima temperado chuvoso (mesotérmico), com inverno seco e verão chuvoso, subtropical. A temperatura média do mês mais frio é inferior a $18^{\circ} \mathrm{C}$ e superior a $3{ }^{\circ} \mathrm{C}$ e o verão apresenta temperatura média do mês mais quente superior a $22^{\circ} \mathrm{C}\left(22,1^{\circ} \mathrm{C}\right.$ em fevereiro). Lavras apresenta temperatura do ar média anual de $19,4{ }^{\circ} \mathrm{C}$, umidade relativa do ar média de 76,2\% e tem precipitação média anual de 1.529,7 mm e evaporação média anual de 1.034,3 mm.

O solo foi classificado como Latossolo Vermelho Distroférrico, textura muito argilosa, com a seguinte composição química na camada de 0 a $0,30 \mathrm{~m}: \mathrm{pH}\left(\mathrm{H}_{2} \mathrm{O}\right)=5,6$; M.O. $=3,0$ dag $\mathrm{kg}^{-1} ; \mathrm{P}=4,3 \mathrm{mg} \mathrm{dm}{ }^{-3} ; \mathrm{K}=119,0 \mathrm{mg} \mathrm{dm}{ }^{-3} ; \mathrm{Ca}^{2+}=1,8$ $\mathrm{cmol}_{\mathrm{c}} \mathrm{dm}^{-3} ; \mathrm{Mg}^{2+}=0,4 \mathrm{cmol}_{\mathrm{c}} \mathrm{dm}^{-3} ; \mathrm{S}=22,7 \mathrm{mg} \mathrm{dm}^{-3} ; \mathrm{Al}^{3+}=0,2$ $\mathrm{cmol}_{\mathrm{c}} \mathrm{dm}^{-3} ; \mathrm{H}+\mathrm{Al}=4,0 \mathrm{cmol}_{\mathrm{c}} \mathrm{dm}^{-3} ; \mathrm{Zn}=9,8 \mathrm{mg} \mathrm{dm}^{-3} ; \mathrm{Fe}=40,1$ $\mathrm{mg} \mathrm{dm}^{-3} ; \mathrm{Mn}=16,4 \mathrm{mg} \mathrm{dm}^{-3} ; \mathrm{Cu}=3,0 \mathrm{mg} \mathrm{dm}^{-3} ; \mathrm{B}=0,9 \mathrm{mg} \mathrm{dm}^{-3}$ $\mathrm{e} V=38,5 \%$.

A curva de retenção da água no solo é representada pela Eq. 1 e na Figura 1:

$$
\theta=0,223+\frac{0,312}{\left[1+(0,2334 .|\Psi|)^{1,7023}\right]^{0,4126}}
$$

em que:

$\theta \quad$ - umidade do solo com base em volume, $\mathrm{cm}^{3} \mathrm{~cm}^{-3}$

$\Psi$ - tensão da água no solo, $\mathrm{kPa}$ 


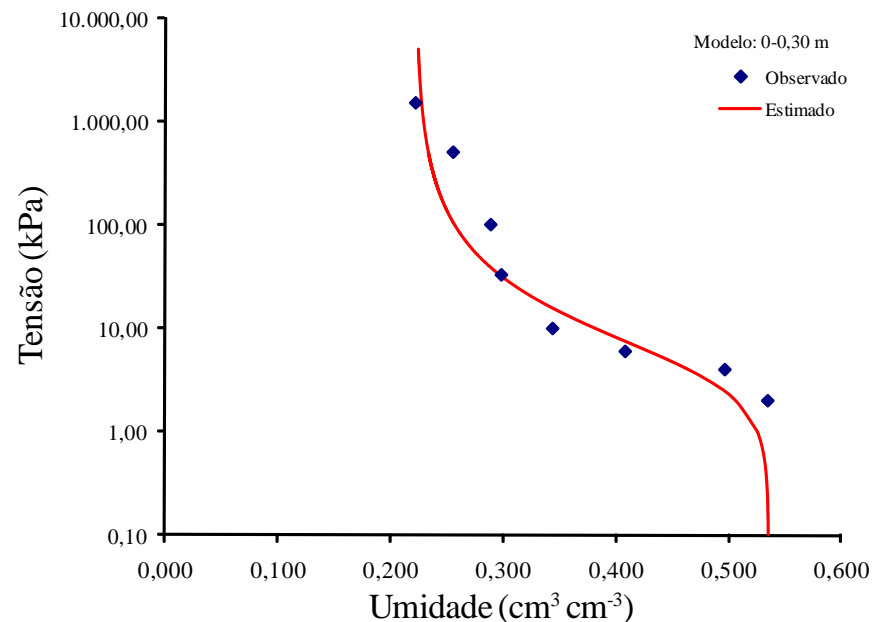

Figura 1. Curva de retenção da água no solo

Empregou-se o delineamento em blocos casualizados (DBC), em esquema fatorial 2 × 6, utilizando-se 12 tratamentos e quatro repetições. Os tratamentos se constituíram de duas cultivares de cenoura, cultivar Nantes $(\mathrm{N})$ e cultivar híbrida Nayarit F1 (HN) e seis tensões da água no solo, 15, 25, 35, 45, 60 e $75 \mathrm{kPa}$ como indicativo do momento de irrigar (tensão crítica). Os tratamentos foram assim representados: N15, N25, N35, N45, N60, N75, HN15, HN25, HN35, HN45, HN60 e HN75. Para monitorar o estado de energia da água no solo foi instalado um conjunto com cinco tensiômetros por parcela (três a $0,15 \mathrm{~m}$ de profundidade para monitorar a irrigação e dois a $0,30 \mathrm{~m}$ de profundidade para verificar a ocorrência de percolação) sendo que, para cada tratamento, os conjuntos de tensiômetros foram instalados em duas das quatro repetições. Os tensiômetros foram instalados no alinhamento da cultura entre duas plantas e ficaram 0,20 m distanciados entre si em cada conjunto.

As parcelas experimentais tiveram dimensões de 1,20 $\mathrm{m}$ de largura por 2,00 m de comprimento $\left(2,40 \mathrm{~m}^{2}\right)$. Utilizaram-se quatro linhas de plantas, espaçadas $0,30 \mathrm{~m}$ entre si e $0,05 \mathrm{~m}$ entre plantas, totalizando 160 plantas por parcela. Foram consideradas úteis as plantas das linhas centrais e descartadas, nessas linhas, cinco plantas, no início e cinco no final (parcela útil de $0,90 \mathrm{~m}^{2}$ com 60 plantas). Após a semeadura, realizada no dia 02/07/2010, a irrigação foi por microaspersão, com o tape SANTENO $^{\circledR}$. Este sistema foi usado até 29 dias após a semeadura, período este necessário para a germinação e uniformidade de pegamento das plantas, no campo. $\mathrm{Na}$ diferenciação dos tratamentos utilizou-se um sistema de irrigação por gotejamento, sendo os emissores autocompensantes e não drenantes, do tipo in-line, modelo NAAN PC com vazão nominal de $1,73 \mathrm{~L} \mathrm{~h}^{-1}$ distanciados entre si a $0,30 \mathrm{~m}$. O tubogotejador ficou posicionado na parcela, de forma a atender às duas fileiras de plantas, trabalhando com pressão de serviço de $140 \mathrm{kPa}$. Buscava-se, em todas as irrigações, elevar, à capacidade de campo, a umidade correspondente à tensão verificada no momento de irrigar, o qual foi estabelecido como aquele em que pelo menos quatro dos tensiômetros de decisão (instalados a $0,15 \mathrm{~m}$ de profundidade) atingiam a tensão crítica estabelecida para cada tratamento. Calculou-se o tempo de funcionamento do sistema de irrigação a partir da lâmina bruta, de acordo com Cabello
(1996), considerando-se a profundidade efetiva do sistema radicular igual a $0,30 \mathrm{~m}$. A eficiência de aplicação de água do sistema de irrigação foi adotada como $95 \%$.

O total de macronutrientes fornecidos para a cultura, ou seja, a soma da adubação de plantio com a de cobertura, esta última realizada via fertirrigação, totalizou a quantidade em kg ha ${ }^{-1}$ de: 120 de $\mathrm{N} ; 320$ de $\mathrm{P}_{2} \mathrm{O}_{5} ; 240$ de $\mathrm{K}_{2} \mathrm{O}$. O total de micronutrientes fornecidos junto com a adubação de plantio, foi de: $2,0 \mathrm{~kg} \mathrm{ha}^{-1}$ de boro e $2,0 \mathrm{~kg} \mathrm{ha}^{-1}$ de zinco.

Realizou-se a colheita no período de 18 a 19/10/2010, de conformidade com o ciclo vegetativo de cada cultivar, com base no comportamento senescêntico das folhas. As plantas foram arrancadas por tratamento e posteriormente as raízes foram lavadas, objetivando-se retirar o excesso de solo das mesmas.

Para obtenção das características avaliadas foram retiradas 20 plantas por parcela de cada tratamento, obtidas a massa total de raízes por parcela e a população de plantas por hectare; estimou-se, então, a produtividade total de raízes. Para a produtividade comercial foram contabilizadas somente raízes que possuíam diâmetro superior a 3,5 cm e perfeitas (ausência de deformação, ombro verde, rachaduras e isenta de ataque de insetos); das raízes comercias obteve-se a massa média por raízes, sendo o descarte classificado como raízes tipo refugo. Avaliou-se, ainda, a eficiência do consumo de água pelas plantas através da relação produção total e quantidade de água consumida por tratamento. Os dados coletados foram submetidos à análise de variância com a realização do teste $\mathrm{F}$, comparação de médias pelo teste de Tukey e análise de regressão polinomial, a 5 e $1 \%$ de probabilidade.

\section{RESULTADOS E DISCUSSÃO}

No período de condução do experimento a temperatura diária média do ar foi de $18,9^{\circ} \mathrm{C}$. Segundo Vieira \& Pessoa (1997) temperaturas entre 10 a $15^{\circ} \mathrm{C}$ contribuem para o alongamento das raízes e para o desenvolvimento de coloração característica, enquanto aquelas superiores a $21^{\circ} \mathrm{C}$ estimulam a formação de raízes curtas e de coloração deficiente. $\mathrm{Na}$ avaliação do sistema obteve-se um coeficiente de uniformidade de distribuição de água (CUD) de 98\%. Suspendeu-se a irrigação da cultura dois dias antes de cada colheita.

As lâminas de água aplicadas antes (Inic) e após a diferenciação dos tratamentos (Irrig), tal como as precipitações ocorridas (Precip), os totais de água fornecidos, para a cultura (Tot) e o número de irrigações (NI) computados, durante a diferenciação dos tratamentos, são apresentados na Tabela 1.

Nota-se, no presente trabalho, que as lâminas totais aplicadas foram superiores nos tratamentos medianos para cada cultivar, admitindo-se um comportamento quadrático em relação ao consumo de água por tratamento; sendo assim, as maiores lâminas foram observadas nos tratamentos intermediários (N35 e HN35) e as menores nos tratamentos extremos (N15 e HN75, HN15 e HN75) para cada cultivar testada neste experimento.

De acordo com a análise de variância (Tabela 2), verificamse efeitos significativos a 1 e $5 \%$ de probabilidade para a produtividade total, produtividade de raízes comerciais, massa 
Tabela 1. Tensões da água no solo na profundidade de $0,15 \mathrm{~m}$, lâminas aplicadas antes da diferenciação dos tratamentos (Inic), lâminas aplicadas após a diferenciação dos tratamentos (Irrig), precipitações ocorridas (Precip), lâminas totais de água (Tot), lâmina média por irrigação (Lmpi.), turno de rega (TR) e número de irrigações (N I)

\begin{tabular}{|c|c|c|c|c|c|c|c|c|}
\hline \multirow{2}{*}{ Tratamentos } & \multirow{2}{*}{$\begin{array}{c}\text { Tensão } \\
\text { (kPa) }\end{array}$} & \multicolumn{5}{|c|}{ Lâmina (mm) } & \multirow{2}{*}{$\begin{array}{c}\text { TR } \\
\text { (dia) }\end{array}$} & \multirow{2}{*}{$\begin{array}{c}\text { NI } \\
\text { (ud) }\end{array}$} \\
\hline & & Inic & Irrig & Precip & Tot & Lmpi & & \\
\hline N15 & 15 & 135,1 & 153,72 & 150,3 & 439,12 & 10,98 & 4,07 & 14 \\
\hline N25 & 25 & 135,1 & 200,16 & 150,3 & 485,56 & 22,24 & 6,33 & 9 \\
\hline N35 & 35 & 135,1 & 224,48 & 150,3 & 509,88 & 28,06 & 7,13 & 8 \\
\hline N45 & 45 & 135,1 & 189,96 & 150,3 & 475,36 & 31,66 & 9,50 & 6 \\
\hline N60 & 60 & 135,1 & 140,44 & 150,3 & 425,84 & 35,11 & 14,25 & 4 \\
\hline N75 & 75 & 135,1 & 112,11 & 150,3 & 397,51 & 37,37 & 19,00 & 3 \\
\hline HN15 & 15 & 135,1 & 142,74 & 150,3 & 428,14 & 10,98 & 4,38 & 13 \\
\hline HN25 & 25 & 135,1 & 177,92 & 150,3 & 463,32 & 22,24 & 7,13 & 8 \\
\hline HN35 & 35 & 135,1 & 224,48 & 150,3 & 509,88 & 28,06 & 7,13 & 8 \\
\hline HN45 & 45 & 135,1 & 189,96 & 150,3 & 475,36 & 31,66 & 9,50 & 6 \\
\hline HN60 & 60 & 135,1 & 140,44 & 150,3 & 425,84 & 35,11 & 14,25 & 4 \\
\hline HN75 & 75 & 135,1 & 112,11 & 150,3 & 397,51 & 37,37 & 19,00 & 3 \\
\hline
\end{tabular}

Tabela 2. Resumo das análises de variância e de regressão para produtividade total de raízes (PTR), produtividade comercial de raízes (PCR), massa média de raízes comerciais ( $M M R C$ ), raízes tipo refugo (refugo) e eficiência do uso da água (EU A) de duas cultivares de cenoura sob diferentes tensões da água no solo

\begin{tabular}{|c|c|c|c|c|c|c|}
\hline \multirow{3}{*}{ Fonte de variação } & \multirow{3}{*}{ G.L. } & \multicolumn{5}{|c|}{ Q.M. } \\
\hline & & PTR & PCR & MMRC & Refugo & EUA \\
\hline & & \multicolumn{2}{|c|}{$\left(\mathrm{kg} \mathrm{ha}^{-1}\right)$} & \multicolumn{2}{|c|}{ (g) } & $\left(\mathrm{kg} \mathrm{ha}^{-1} \mathrm{~mm}^{-1}\right)$ \\
\hline Bloco & 3 & $81021761,38^{*}$ & $12130461,44^{\mathrm{ns}}$ & $29,38^{\mathrm{ns}}$ & 99,29 ns & $2673,57^{\text {ns }}$ \\
\hline Cultivares & 1 & $597371546,29^{* *}$ & $424808580,27^{*}$ & $954,08^{*}$ & $25,53^{\text {ns }}$ & $82860,53^{* *}$ \\
\hline Tensões & 5 & $716414146,29^{* *}$ & $2,67594159 \mathrm{E} 9^{* *}$ & $6017,70^{* *}$ & $1869,27^{* *}$ & $2254,87^{* *}$ \\
\hline Cultivares $x$ Tensões & 5 & $59409994,56^{\mathrm{ns}}$ & $72137150,67^{\text {ns }}$ & $158,68^{\mathrm{ns}}$ & $327,57^{\mathrm{ns}}$ & $2254,87^{\mathrm{ns}}$ \\
\hline Resíduo & 33 & 28836318,99 & 73175974,84 & 165,93 & 166,46 & 1066,54 \\
\hline Média & - & 77666,66 & 42346,83 & 63,50 & 52,93 & 482,93 \\
\hline C.V. (\%) & - & 6,70 & 20,20 & 20,29 & 24,37 & 6,76 \\
\hline Tensões & 5 & $716414146,29^{* *}$ & $2,67594159 \mathrm{Eg}^{* *}$ & $6017,70^{* *}$ & $1869,27^{* *}$ & $2254,87^{* *}$ \\
\hline Linear & 1 & $3097481660,85^{* *}$ & $13035586963,09^{* *}$ & $29307,66^{* *}$ & $7704,83^{* *}$ & $11652,09^{* *}$ \\
\hline Quadrática & 1 & 72400321,79 ns & $175548503,66^{\mathrm{ns}}$ & 394,18 ns & $1061,94^{* *}$ & $365609,07^{* *}$ \\
\hline Desvios & 3 & $137396249,61^{*}$ & 56190831,99 ns & $128,88^{\text {ns }}$ & $193,13^{\text {ns }}$ & $12347,17^{* *}$ \\
\hline
\end{tabular}

ns - não significativo pelo teste $\mathrm{F}_{\text {, }}{ }^{*} \mathrm{e}^{* *}$ - significativos a 5 e $1 \%$ de probabilidade pelo teste $\mathrm{F}$, respectivamente

média de raízes comerciais e eficiência do uso da água, com relação aos fatores cultivares e tensões da água no solo; para a variável raízes tipo refugo observa-se efeito significativo somente para o fator tensão; já a interação entre os fatores não apresentou diferença significativa a $5 \%$ de probabilidade, para essas características estudadas.

Constata-se, pelo teste de médias (Tabela 3), que a maior produtividade total e comercial de raízes foi obtida utilizandose a cultivar hibrida Nayarit F1, quando comparada à cultivar Nantes, independente dos outros fatores considerados, indicando que a possível diferença possa ter sido função apenas do fator genético.

Tabela 3. Médias de produtividade total de raízes (PTR), produtividade comercial de raízes (PCR), massa média de raízes comerciais (M M RC) e eficiência do uso da água (EU A) de duas cultivares de cenoura sob diferentes tensões da água no solo

\begin{tabular}{|c|c|c|c|c|}
\hline \multirow{2}{*}{ Cultivares } & PTR & PCR & \multirow{2}{*}{$\begin{array}{c}\text { MMRC } \\
\text { (g) }\end{array}$} & \multirow{2}{*}{$\begin{array}{c}\text { EUA } \\
\left(\mathrm{kg} \mathrm{ha}^{-1} \mathrm{~mm}^{-1}\right)\end{array}$} \\
\hline & \multicolumn{2}{|c|}{$\left(\mathrm{kg} \mathrm{ha}^{-1}\right)$} & & \\
\hline Nantes & 74138,88 b & 39371,90 & $59,04 \mathrm{~b}$ & $454,45 \mathrm{~b}$ \\
\hline Hibrido & $81194,44 a$ & $45321,75 \mathrm{a}$ & 67,95 a & $511,41 \mathrm{a}$ \\
\hline
\end{tabular}

${ }^{1}$ Médias seguidas por letras diferentes diferem, estatisticamente entre si, pelo teste de Tukey, a $5 \%$ de probabilidade
A produtividade total média de ambas as cultivares testadas neste trabalho encontra-se abaixo daquela encontrada por Resende \& Cordeiro (2007), em Petrolina, PE, que, ao trabalhar com a cultivar Brasília em função da qualidade da água e condicionamento de solo encontraram, para esta cultivar, uma produtividade total média de $82.000,3 \mathrm{~kg} \mathrm{ha}^{-1}$. Trabalhando com diferentes densidades populacionais para as cultivares Brasília, Alvorada e Esplanada, Lopes et al. (2008) encontraram produtividade total média de $39.000,32.000$ e $31.000 \mathrm{~kg} \mathrm{ha}^{-1}$, respectivamente; entretanto, as produtividades totais médias de raízes obtidas neste trabalho, de $81.194,44 \mathrm{~kg} \mathrm{ha}^{-1}$ para o híbrido Nayarit F1 e de 74.138,88 $\mathrm{kg} \mathrm{ha}^{-1}$ para a cultivar Nantes, foram superiores à média das principais regiões produtoras do país que, segundo CEPEA (2010), foi de $72.000 \mathrm{~kg} \mathrm{ha}^{-1}$ de raiz. Luz et al. (2009) estudaram diferentes cultivares de cenoura na região pertencente ao município de Uberlândia,MG, e obtiveram, para a cultivar Nantes, produtividade comercial máxima de 20.500 $\mathrm{kg} \mathrm{ha}^{-1}$, enquanto Pessoa \& Cordeiro (1997) verificaram valor máximo para a cultivar Brasília de $76.700 \mathrm{~kg} \mathrm{ha}^{-1}$ nas condições do Distrito Federal, valores extremos encontrados por esses autores quando comparados com os obtidos neste trabalho. Na mesma linha de pesquisa Oliveira et al. (2008) obtiveram, testando várias cultivares no município de São José do Rio 
Pardo,SP, para as cultivares Alvorada, Nova Brasília, Brazlândia, Brasília' [1], 'Brasília'[2], 'Brasília-RL', 'Carandaí, 'Tropical' e 'HT-2000' produtividades médias de 28.580; 27.360; 32.010; 26.510; 26.290; 26.000; 25.410; 25.130 e $23.390 \mathrm{~kg} \mathrm{ha}^{-1}$ de raízes comerciais, respectivamente, resultados inferiores do apresentado neste trabalho. As variações de resultados de produtividades apresentados pelos autores em comparação com o apresentado neste trabalho, podem ser explicadas em parte pelo potencial genético que cada cultivar apresenta e as condições edafoclimáticas nas quais as mesmas foram cultivadas.

De acordo com o teste de médias (Tabela 3), o melhor comportamento observado quando se avaliou a massa média de raízes comercias foi obtido pelo híbrido Nayarit F1, apresentando valor $67,95 \mathrm{~g}$, resultado que representa incremento médio de $13,1 \%$ em relação à massa média da cultivar Nantes. Avaliando diferentes espaçamentos em duas cultivares de cenoura, Bernardi et al. (2004) obtiveram 81,5 e 49,7 grama por planta quando utilizaram as cultivares AF845 e AF750, respectivamente. Luz et al. (2009) estudaram diferentes níveis de salinidade na cultura da cenoura cv. Brasília, e obtiveram, neste estudo, o valor máximo de 80,9 grama por planta quando as plantas foram submetidas ao tratamento com água normal a $0,1 \mathrm{dS} \mathrm{m}{ }^{-1}$. Os valores máximos encontrados pelos autores, estão acima dos valores encontrados neste trabalho, sendo interessante frisar que tanto o ambiente e a cultivares utilizadas em ambos os experimentos são distintos, demonstrando a importância em se realizar esses tipos de trabalhos para cada local distinto com o intuito de maximizar a produtividade da região. Nota-se, pelo teste de médias (Tabela 3), que o híbrido Nayarit F1 se apresentou mais eficiente $(11,1 \%)$ no uso da água, para a produtividade total de raízes do que a cultivar nantes. Este fato é justificado pela maior produtividade total média de raízes e, também, pelo menor consumo de água pela planta (Tabela 1), observado para esta cultivar no tratamento referente à tensão de $15 \mathrm{kPa}$.

As variáveis analisadas neste trabalho foram influenciadas pelas tensões da água no solo e representadas por regressão média das duas cultivares (Figura 2). Os resultados da produtividade total, comercial e massa média de raízes comerciais, demonstraram resposta linear com nível de significância de $1 \%$ (Tabela 2), indicando um decréscimo no valor dessas variáveis à medida em que se aumentaram as tensões da água no solo. O valor máximo para a produtividade total e comercial de raízes de cenoura ocorreu na tensão de 15 $\mathrm{kPa}$, resultando em produtividades de 88.516,5 e 64.604,5 $\mathrm{kg} \mathrm{ha}^{-1}$, respectivamente (Figura 2A). Objetivando maximizar a produtividade de raízes de cenoura, Marouelli et al. (2007) recomendam que as irrigações via gotejo devam ser reiniciadas quando a tensão-limite atingir de 7 a $20 \mathrm{kPa}$. Verifica-se que a máxima produtividade encontrada neste trabalho se situa dentro do intervalo de tensão sugerido para maximização da produtividade recomendada por esses autores.

Raízes de beterraba irrigadas com água salina sob diferentes lâminas de lixiviação, foram avaliadas por Ferreira et al. (2006) em Viçosa, MG, e apresentaram rendimento médio obtido de $37.500 \mathrm{~kg} \mathrm{ha}^{-1}$ contudo, sem diferença significativa entre os tratamentos. A produtividade obtida pelo autor demonstra o
A.
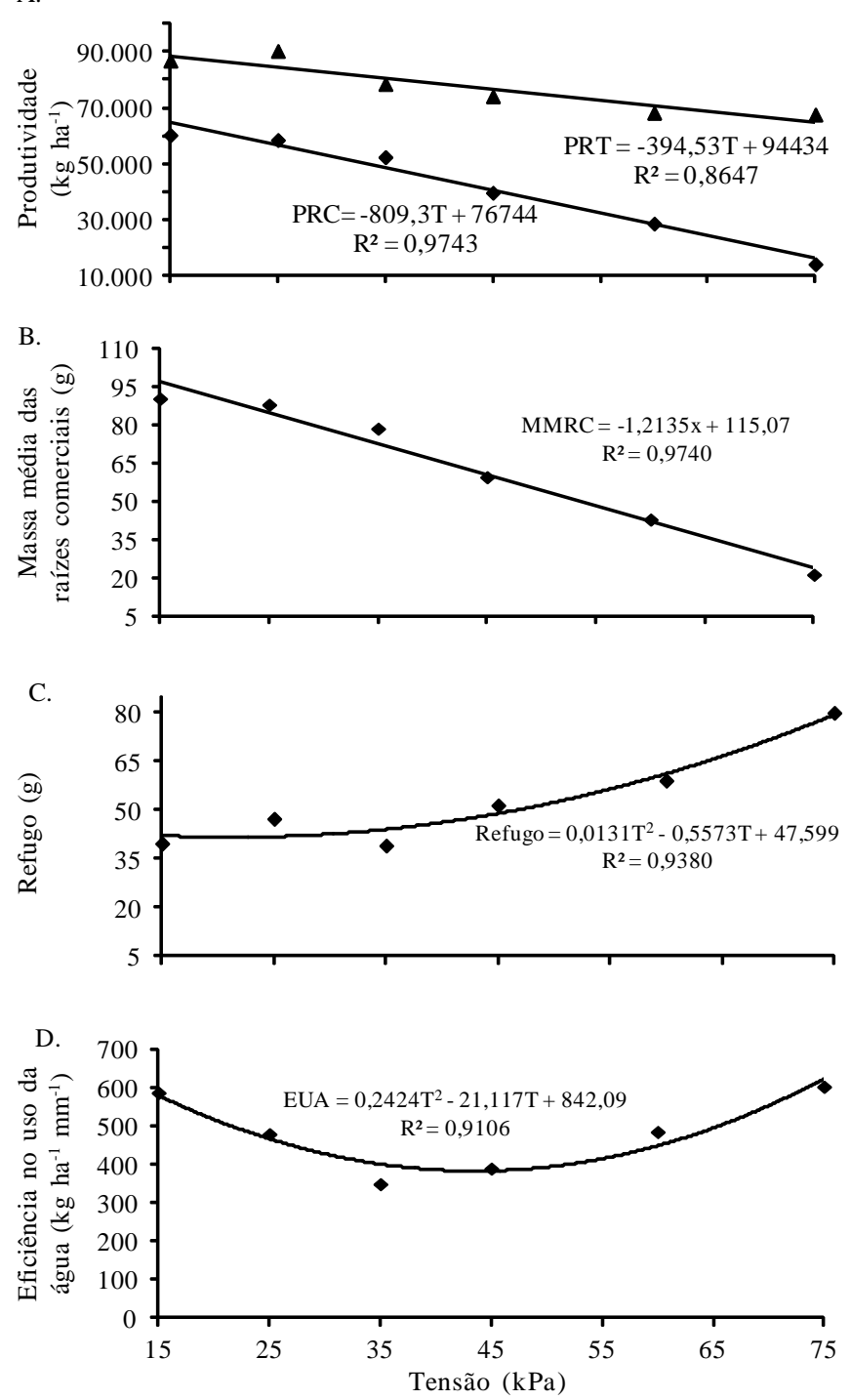

Figura 2. Produtividade total de raízes (PTR) e produtividade de raízes comerciais (PRC) $(A)$, massa média de raízes comerciais (MMRC) (B), raízes tipo refugo (Refugo) (C) e eficiência no uso da água (EU A) (D) de cenoura em função das diferentes tensões da água no solo

potencial da cultura de se desenvolver em condições de elevadas tensões de água no solo.

Comportamento semelhante obtiveram Silva et al. (1982) na cultura da cenoura cv. Nantes irrigada por aspersão, quando aumentaram os valores de tensão da água no solo. Referidos autores estudaram quatro valores tensões (19, 24, 29 e 33 kPa) e encontraram redução na produtividade comercial de raízes, com o aumento da tensão, sendo que não houve diferença significativa entre as tensões de 19, 24 e $29 \mathrm{kPa}$, apresentando valores totais de produtividades em padrão comercial de 37.790 , 30.880 e $26.550 \mathrm{~kg} \mathrm{ha}^{-1}$, respectivamente; já com a tensão de 33 $\mathrm{kPa}$ a produtividade foi de $173120 \mathrm{~kg} \mathrm{ha}^{-1}$.

O mesmo comportamento linear foi encontrado por VilasBoas et al. (2011) que, visando definir critérios para o manejo da irrigação por gotejamento na cultura da cebola, avaliaram seis tensões da água no solo $(15,25,35,45,60$ e $75 \mathrm{kPa})$, medidas a $0,20 \mathrm{~m}$ de profundidade e constataram que a produtividade 
de bulbos comerciais apresentou resposta linear decrescente com o aumento da tensão, alcançando o valor máximo de $47.729,9 \mathrm{~kg} \mathrm{ha}^{-1}$ com a tensão de $15 \mathrm{kPa}$.

A tensão limite para reiniciar as irrigações neste trabalho está dentro do intervalo recomendado por Shock et al. (2002), ao afirmarem que as irrigações devem ser realizadas sempre que o potencial matricial estiver entre 15 a $30 \mathrm{kPa}$, intervalo considerado ideal pelos autores para obtenção de máximo rendimento de raízes comerciais por hectare. Moura et al. (1994) obtiveram, utilizando a metodologia do balanço hídrico de água no solo, um consumo de 365,03 mm de água para a cultura da cenoura cv nantes nas condições de Piracicaba, SP, no intervalo de 101 dias de ciclo vegetativo. Este valor de lâmina consumido está acima somente do tratamento N75 que corresponde à cultivar nantes versus tensão de $75 \mathrm{kPa}$; ressalta-se que o ciclo da cultura neste experimento foi de 110 dias.

De acordo com a equação apresentada na Figura $2 \mathrm{~B}$, o aumento de uma unidade $(\mathrm{kPa})$ na tensão da água no solo reduz em 1,21 g a massa de raízes comerciais. $\mathrm{O}$ valor máximo encontrado para a variável estudada ocorreu na tensão de 15 $\mathrm{kPa}$, resultando em um valor máximo de raízes comerciais de 96,86 g. Moura et al. (1994) obtiveram, utilizando a metodologia do balanço hídrico de água no solo, um consumo de 365,03 mm de água para a cultura da cenoura cv nantes nas condições de Piracicaba, SP, no intervalo de 101 dias de ciclo vegetativo, valor bastante inferior ao encontrado neste trabalho, para todos os tratamentos realizados.

Observando a equação apresentada na Figura 2C, o valor máximo de raízes tipo refugo foi encontrado com a tensão de 75 $\mathrm{kPa}$ correspondente ao valor de 79,47 g. O valor mínimo encontrado para a variável estudada ocorreu na tensão de 21 $\mathrm{kPa}$, resultando em um valor mínimo de massa de refugo de 41,67 g. Observa-se, na Figura 2C, que as menores tensões de água no solo proporcionaram valores menores de refugo evidenciando que para baixas tensões a probabilidade de obtenção de raízes em padrão comercial se torna maior, valor este em torno de $21 \mathrm{kPa}$. De acordo com Costa et al. (2006) variações de umidade e temperatura no solo durante o desenvolvimento das plantas podem prejudicar a produtividade e a qualidade das raízes. Kumar et al. (2007), também encontraram comportamento semelhante para a classificação de bulbos de cebola em função da irrigação; segundo eles, a porcentagem de bulbos em padrão comercial foi obtida nos tratamentos em que foram aplicados os maiores níveis de irrigação refletindo, assim, que a umidade influencia diretamente na menor percentagem de bulbos tipo refugo. É provável que a restrição hídrica tenha influenciado decisivamente no número de raízes fora do padrão comercial, neste trabalho.

Em relação à eficiência do uso da água as variações ocorridas podem ser explicadas pela regressão quadrática, a $1 \%$ de probabilidade (Tabela 2). Nota-se, pela Figura 2D, que a maior eficiência no consumo de água foi verificada nos tratamentos extremos, ou seja, a tensão de 15 e $75 \mathrm{kPa}$, atingindo valores de 579,87 e $621,81 \mathrm{~kg} \mathrm{ha}^{-1} \mathrm{~mm}^{-1}$, respectivamente. Amenor resposta de eficiência para esta variável ocorreu com a tensão de $43 \mathrm{kPa}$, que corresponde ao valor de $382,26 \mathrm{~kg} \mathrm{ha}^{-1} \mathrm{~mm}^{-1}$. Alguns trabalhos da literatura, realizados com outras hortaliças, mostraram que com o acréscimo da tensão da água e/ou com o decréscimo da lâmina de água aplicada, a eficiência tende a aumentar progressivamente (Lima Júnior et al., 2010; 2011; VilasBoas et al., 2011); no entanto, neste trabalho o comportamento foi verificado a partir da tensão de $43 \mathrm{kPa}$, conforme a Figura 2D.

Houve acréscimo na eficiência do uso da água com a diminuição da tensão entre 43 até $15 \mathrm{kPa}$. Resultado semelhante foi encontrado por Coelho et al. (1996) que obtiveram maiores valores de eficiência no uso da água com a diminuição da tensão da água no solo na cultura da cebola em função de três regimes de irrigação e cinco espaçamentos.

\section{Conclusões}

1. O híbrido Nayarit F1 apresentou melhores respostas com relação às seguintes características analisadas: produtividade total de raízes, produtividade de raízes comerciais, massa média de raízes comerciais e eficiência no uso da água.

2. Visando à obtenção de maiores produtividades de bulbos (total e comercial) e maior massa média de bulbos comerciais, em ambas as cultivares, deve-se irrigar no momento em que a tensão da água no solo estiver em torno de $15 \mathrm{kPa}$ na profundidade de $0,15 \mathrm{~m}$.

3. O valor mínimo encontrado para as raízes do tipo refugo ocorreu na tensão de $21 \mathrm{kPa}$, resultando em um valor mínimo de massa raiz de $41,67 \mathrm{~g}$.

4. A maior eficiência no consumo de água foi verificada nos tratamentos extremos, com tensão de 15 a $75 \mathrm{kPa}$, atingindo valores de 579,87 e $621,81 \mathrm{~kg} \mathrm{ha}^{-1} \mathrm{~mm}^{-1}$, respectivamente.

\section{AgRAdeCIMENTOS}

À Coordenação de Aperfeiçoamento de Pessoal de Nível Superior (CAPES), pela concessão da Bolsa de Auxílio; ao Conselho Nacional de Desenvolvimento Científico e Tecnológico (CNPq), pela concessão das Bolsas de Produtividade e de Iniciação Científica e ao Departamento de Engenharia da UFLA.

\section{LITERATURA CITADA}

Bernardi, W. F.; Freitas, J. A.; Silva, V. A. R.; Tulmann Neto, A. Avaliação de espaçamentos de cenoura para os híbridos AF845 e AF750. Acta Scientiarum, v.26, p.125-130, 2004.

Cabello, F. P. Riegos localizados de alta frecuencia (RLAF) goteo, microaspersión, exudación. 3.ed. Madrid: Ediciones Mundi-Prensa, 1996. 511p.

CEPEA - Centro de Estudos Avançados em Economia Aplicada da Escola Superior de Agricultura "Luiz de Queiroz"/ Universidade de São Paulo. In: Hortifruti Brasil. Piracicaba: ESALQ/USP, 2010. p.26-28.

Coelho, E. F.; Souza, V. A. B.; Conceição, M. A. F. Comportamento da cultura da cebola em três regimes de irrigação e cinco espaçamentos. Pesquisa Agropecuária Brasileira, v.31, p.585-591, 1996. 
Costa, C. C.; Oliveira, C. D.; Silva, C. J.; Timossi, P. C.; Leite, I. C. Crescimento, produtividade e qualidade de raízes de rabanete cultivadas sob diferentes fontes e doses de adubos orgânicos. Horticultura Brasileira, v.24, p.118-122, 2006.

Dantas, A. A. A.; Carvalho, L. G.; Ferreira, E. Classificação e tendência climática em Lavras, MG. Ciência e Agrotecnologia, v.31, p.1862-1866, 2007.

Ferreira, P. A.; Moura, R. F.; Santos, D. B. dos; Fontes, P. C. R.; Melo, R. F. Efeitos da lixiviação e salinidade da água sobre um solo salinizado cultivado com beterraba. Revista Brasileira de Engenharia Agrícola e Ambiental, v.10, p.570-578, 2006.

Kumar, S.; Imtiyaz, M.; Kumar, A.; Singh, R. Response of onion (Allium cepa L.) to different levels of irrigation water. Agricultural Water Management, v.89, p.161-166, 2007.

Lima Júnior, J. A.; Pereira, G. M.; Geisenhoff, L. O.; Costa, G. G.; Reis, R. P.; Oliveira, L. F. C. Avaliação econômica da produção de alface americana em função de lâminas de irrigação. Ciência e Agrotecnologia, v.35, p.392-398, 2011.

Lima Júnior, J. A.; Pereira, G. M.; Geisenhoff, L. O.; Costa, G. G.; Vilas Boas, R. C.; Yuri, J. E. Efeito da irrigação sobre o rendimento produtivo da alface americana, em cultivo protegido. Revista Brasileira de Engenharia Agrícola e Ambiental, v.14, p.797-803, 2010.

Lopes, W. A. R.; Negreiros, M. Z.; Teófilo, T. M. S.; Alves, S. S. V.; Martins, C. M.; Nunes, G. H. S.; Grangeiro, L. C. Produtividade de cultivares de cenoura sob diferentes densidades de plantio. Revista Ceres, v.55, p.482-487, 2008.

Luz, J. M. Q; Silva Júnior, J. A.; Teixeira, M. S. S. C.; Silva, M. A. D; S. G. M; Melo, B. Desempenho de cultivares de cenoura no verão e outono-inverno em Uberlândia-MG. Horticultura Brasileira, v.27, p.96-99, 2009.

Marouelli, W. A.; Oliveira, R. A.; Silva, W. L. C. Irrigação da Cultura da Cenoura. Brasília: Embrapa Hortaliças, 2007.14p.Circula Técnica, 48.

Moura, M. V. T.; Marques Júnior, S.; Botrel, T. A.; Frizone, J. A. Estimativa do consumo de água na cultura da cenoura (Daucus carota, 1.) v. nantes superior, para a região de piracicaba, através do método do balanço hídrico. Scientia Agricola, v.51, p.284-291, 1994.
Morgan, K. T.; Parsons, L. R.; Wheaton, T. A. Comparison of laboratory and field, derived soil water retention curves for a fine sand soil using tensiometric resistance and capacitance methods. Plant and Soil, v.234, p.153-157, 2001.

Nogueira, L. C.; Nogueira, L. R. Q.; Miranda, F. R. Irrigação do coqueiro. In: Ferreira, J. M. S.; Warwick, D. R. N.; Siqueira, L. A. (ed.). A cultura do coqueiro no Brasil. 2.ed. Brasília: Embrapa SPI; Aracaju: Embrapa CPATC, 1998. p.159-187.

Oliveira, C. D.; Braz, L. T.; Banzatto, D. A. Adaptabilidade e estabilidade fenotípica de cultivares de cenoura. Revista Brasileira de Horticultura, v.26, p.88-92, 2008.

Pessoa, H. B .S. V.; Cordeiro, C. M. T. Avaliação de cultivares de cenoura no outono-inverno no Distrito Federal. Horticultura Brasileira, v.15, p.72-74, 1997.

Resende, G. M.; Cordeiro, G. G. Produtividade da cenoura em função da qualidade da água e condicionador de solo no Vale do São Francisco. Revista Caatinga, v.20, p.100-104, 2007.

Shock, C.; Feibert, E.; Eldredge; E.; Saunders, M.; Butler, M.; Campbell, C.; Crowe, F.; Sexton, P.; Klauzer, J. Progress report on microirrigation in Oregon. New Orleans: Central Oregon Agricultural Research Center, 2002. 102p.

Silva, L. C.; Vieira, J. V.; Carrijo, O. A. Efeito de diferentes tensões de umidade do solo sobre a cultura da cenoura em fase de desenvolvimento ativo do sistema radicular. Pesquisa Agropecuária Brasileira, v.17, p.211-214, 1982.

Simon, P. W. Domestication, historical development, and modern breeding of carrot. Plant Breeding Reviews, v.19, p.157-190, 2000.

Vilas Boas, R. C.; Pereira, G. M.; Souza, R. J.; Consoni, R. Desempenho de cultivares de cebola em função do manejo da irrigação por gotejamento. Revista Brasileira de Engenharia Agrícola e Ambiental, v.15, p.117-124, 2011.

Vieira, J. V.; Pessoa, H. B. V. Cultivo da cenoura: Clima. Instruções Técnicas da Embrapa Hortaliças. Brasília: EMBRAPA, 1997. $1 \mathrm{p}$. 